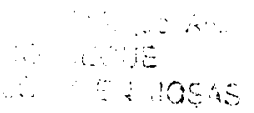

$\div, 95.5$

Review

\title{
Resistance of livestock to viruses: mechanisms and strategies for genetic engineering
}

\author{
JS Gavora \\ Centre for Food and Animal Research, Agriculture and Agri-Food Canada, Ottawa, \\ ON K1A oC6 Canada
}

(Received 26 March 1996; accepted 13 August 1996)

\begin{abstract}
Summary - This communication aims to inform readers from research and industry about the possibilities of developing genetic engineering strategies for improvement of resistance to viruses in livestock. It briefly reviews coevolution of hosts and parasites, principal elements of virus-host interactions, existing resistance mechanisms, and conventional methods for improvement of disease resistance. Research results from genetic engineering of new resistance mechanisms in both plants and animals, as well as investigation of possible risks and 'biological cost' of such mechanisms are summarized as a background for the discussion of prerequisites and strategies for future genetic engineering of resistance to viruses in livestock. It is concluded that, while conventional breeding methods will remain the principal approach to the improvement of disease resistance, in some instances the introduction of new, genetically engineered resistance mechanisms may be justified.
\end{abstract}

livestock / virus / resistance mechanism / genetic engineering

Résumé - Résistance des animaux de ferme aux virus: mécanismes et stratégies de génie génétique. Cette mise au point vise à informer les chercheurs et les professionnels des possibilités qu'offre le génie génétique pour améliorer la résistance aux virus des animaux de ferme. Le rapport passe en revue la coévolution hôte-parasite, les principaux aspects des interactions virus hôte, les mécanismes de résistance existants et les méthodes classiques d'amélioration de la résistance aux maladies. Les résultats des recherches sur la mise en ouvre par génie génétique de nouveaux mécanismes de résistance tant animale que végétale sont résumés, ainsi que l'étude des risques possibles et du "coût biologique» de ces mécanismes. Ces considérations constituent la toile de fond de la discussion sur les conditions requises et les stratégies pour, à l'avenir, améliorer par génie génétique la résistance aux virus chez les animaux de ferme. La conclusion tirée est que, à côté des méthodes classiques de sélection qui resteront la principale voie d'amélioration, dans certains cas il peut être justifié d'introduire de nouveaux mécanismes de résistance par génie génétique.

animal / virus / mécanisme de résistance / génie génétique 


\section{INTRODUCTION}

Maximum survival of livestock, with good health and well being are conditions for efficient animal production. Many of the current livestock disease problems that prevent the realization of this optimal production goal are caused by viruses, described by Peter Medawar as "pieces of bad news wrapped in protein coat". This review deals with possible new, genetic engineering strategies for the improvement of resistance to viruses in livestock. Since work on genetic engineering of disease resistance is more advanced in plants than in livestock, information on research in plants is also reviewed.

The use of livestock for food, fibre and draft over hundreds of years has led to a significant influence by humans on the evolution of domesticated animal species. Some of the changes induced by artificial selection parallel in their significance speciation. A modern meat-type chicken can be viewed as a species different from a modern egg-type chicken. Similar differences exist between breeds of dairy and beef cattle. This 'genetic engineering' of livestock was achieved through the long-term use of conventional genetic improvement methods. It can be argued that gene transfer represents just another phase in the development of genetic engineering of livestock and that it would be foolish not to take advantage of the new technologies. Thus introduction of new mechanisms of disease resistance in livestock by gene transfer may be viewed as a logical continuation of the creative influence of humans on the evolution of farm animals and birds that could benefit mankind by improvements in food safety and production efficiency. Increased disease resistance will also improve the welfare of livestock. The latter consequence may make this type of genetic engineering more acceptable to the general public than other types of gene transfer.

If there is one attribute that is common to viruses, it is the lack of uniformity in all aspects of their existence. Nevertheless, this review attempts to find general elements and common patterns in the subject discussed. As background for the discussion of the subject, the article deals briefly with coevolution of hosts and parasites and principal elements of virus-host interactions, and reviews past improvement of disease resistance in plants and livestock by conventional breeding and genetic engineering, as well as the potential 'biological cost' of genetic manipulation. It includes prerequisites for and principles of the design of new resistance mechanisms, and proposes possible strategies for the introduction of disease resistance mechanisms by gene transfer.

The main goal of this review is to inform readers from both research and industry about this area of long-term interest to animal agriculture and outline the potential use of the concept of new resistance mechanisms for the benefit of mankind and improvement of animal welfare.

\section{COEVOLUTION OF HOSTS AND VIRUSES}

Basic understanding of the parallel evolution of viruses and their hosts provides a useful starting point for the consideration of strategies for genetic engineering of new mechanisms of resistance. Therefore, principal elements of the coevolution of viruses and hosts are briefly reviewed. 
Viruses are obligatory, intracellular parasistes with limited genome sizes that code for functions the virus cannot adopt from host cells (Strauss et al, 1991). Viruses have their own evolutionary histories, independent of those of their hosts. It is not clear whether viruses had a single or multiple origin. The origin of a virus is defined as that time when its replication and evolution became independent of the macromolecules from which it was derived (Strauss et al, 1991). Viruses may have arisen (1) by selection from an organelle; (2) from cellular DNA or RNA components that donate macromolecules which gain the ability to replicate and evolve independently; or (3) from self-replicating molecules. Polymers of ribonucleotides can contain both the information required and the functional capacity to form a self-replicating system (Watson et al, 1987).

The main mechanisms of viral evolution are mutation, recombination, and gene duplication. Viruses have a very short generation interval and high mutation rate. For example, the mutation rate of a chicken retrovirus is $10^{-5}$ nucleotide/replication cycles - approximately eight orders higher than that of the host cell genome (Dougherty and Temin, 1988). Nevertheless, the virus always retains its origin of replication. Recombination has also a large role in viral evolution because it allowed viruses to 'try out new gene combinations'. An example of an unusual acquisition of genes by a virus are three tRNA genes in bacteriophage T4a type of gene only observed in eukaryotes (Gott et al, 1986). Although it is possible that the genes evolved within T4, the phage may also have acquired the genes from an eukaryotic host (Michel and Dujon, 1986). Similarly some retroviruses such as Rous sarcoma virus acquired oncogenes for their genome.

In general, DNA viruses are more stable than RNA viruses and do not cause rapidly moving pandemics as is the rule for RNA viruses; in contrast, DNA viruses tend to establish persistent or latent infections which may lead to malignant transformations (Strauss et al, 1991). Exceptions to the general rule include the herpesvirus of Marek's disease, a DNA virus that can cause rapidly moving disease outbreaks in chickens, and the avian leukosis viruses, RNA viruses that exhibit a period of latency and seldom cause high mortality.

A disease of the host is not an evolutionary goal of the parasite. Compatibility is preferable to incompatibility. Subclinical infections are common; they are the rule - diseases the exception. There is no selective advantage to the virus in making the host ill, unless the disease aids in the transmission of the virus to new hosts, such as in the case of diarrhea. In some instances, disease may also result from an overzealous immune system. Hence the interplay between microbes and hosts should not necessarily be seen as an ongoing battle but as a coevolution of species (Pincus et al, 1992).

\section{PRINCIPAL ELEMENTS OF VIRUS-HOST INTERACTIONS}

\section{General considerations}

Susceptibility (in the narrow sense) is the capacity of cells to become infected. For a virus to survive and reproduce, essential viral genes have to ensure: (1) replication of viral genomes in which the involvement of viral genes varies from assisting host 
enzymes, to actually replicating the viral genome, although even the most selfdependent viruses use some host cell function in the process; (2) packaging of the genome into virus particle - viral proteins do the packaging, although host proteins may complex with viral ones in the process; and (3) alteration of the structure or function of the infected cell - the effects may range from cell destruction to subtle, but significant changes in function and antigenic specificity of infected cells. In general, once it enters, no virus leaves a cell unchanged.

During their replication, viruses exploit host cell molecules at the expense of the cells. There are three types of viral infection (Knipe, 1991). (1) In nonproductive cases the infection is blocked because the cell lacks a component essential for viral replication. The viral genome may be lost or remain integrated in the host genome. The cell may or may not survive or, if growth properties of the cells are altered by the virus, oncogenic transformation may take place. (2) Productive infection is when the cell produces the virus but, as a consequence, dies and lyses. (3) Productive infection is when the cell survives and continues to produce the virus.

The levels of injury to the cells resulting from viral infection range from no visible effects to cell death and include inclusion body or syncytium formation and cell lysis. In most instances cell injury is a consequence of processes necessary for virus replication but at least in one known instance, the penton protein of the adenovirus, which has no known purpose in the viral cycle, causes cytopathic effects in monolayer cells (Valentine and Pereira, 1965).

Genetic engineering strategies that prevent entry of viruses into host cells would be effective against all three types of viral infection. Other strategies discussed below can deal with various stages of viral life cycles and would accordingly affect the outcome of viral infection.

To provide a basis for the examination of the opportunities to devise and genetically engineer new resistance mechanisms, the viral life cycle that consists of three fundamental steps, attachment, penetration, and replication (Roizman, 1991) will be examined in sequence.

\section{Attachment of virus to the host cell}

Attachment of the virus to the host cell is, in most instances, through a specific binding of a virion protein, the antireceptor, to a constituent of the cell surface, the receptor. Complex viruses, such as vaccinia, may have more than one species of antireceptor or antireceptors may have several domains, each reacting with a different receptor. Mutations of receptors may cause a loss of the capacity of a receptor and antireceptor to interact and thus lead to resistance to viral infection. It seems likely that mutations in antireceptors preventing viral attachment will be automatically eliminated from viral evolution, unless they are able to interact with a substitute host.

The number of receptors for which information is accumulating is rapidly increasing. Examples in table I show that receptors are mostly glycoproteins. Not all cells in a susceptible organism express viral receptors, a phenomenon that may limit susceptibility. Even though our understanding of receptors is still at an early stage, it is obvious that viral receptors are molecules that have a normal physiological function in the host. 
While there is a great deal of variability in the types of molecule in viral receptors, some cell surface molecules are used by multiple, often unrelated viruses (table I). When viewed across host species, for example, histocompatibility molecules are receptors for both Semliki-Forest togavirus and human coronavirus; sialic acid residues serve as receptors for both the influenza myxovirus and reoviruses, although there are rotaviruses that do not require their presence (Mendez et al, 1993) and low density lipoproteins (LDL) are receptors for both the human minor cold picorna virus and avian leukosis viruses.

Viruses compete with molecules that require receptors for a physiological function of the host. For example, LDL and the human minor rhinovirus compete for LDL receptors (table I), and cells with down-regulated LDL receptor expression yield much less virus than up-regulated cells (Hofer et al, 1994). Viruses tend to use abundant molecules as receptors, so that reduction in availability of the molecules for the physiological function is not lethal, or molecules whose function can be substituted by other molecules. There are alternative viral strategies to deal with the receptor problem. The part of the sodium-independent transporter of cationic amino acids, used as the receptor for ecotropic bovine leukemia virus (table I), is different from the part of the protein directly involved in the amino-acid transport function. Thus the physiological function of the receptor can continue, despite binding of virus to the receptor (Wang et al, 1994). Another example confirming this possibility is the sodium-dependent transporter of inorganic phosphate that serves as the receptor for the gibbon ape leukemia virus (table I). Productive infection of cells expressing this receptor results in complete blockage of the uptake of inorganic phosphate mediated by the receptor. Nevertheless, the infection is not cytotoxic. Hence, there is likely more than one phosphate transport mechanism in these cells (Olah et al, 1994). This aspect of viral strategies may open up possibilities to block the receptor sites, thus preventing entry of a virus without serious impairment of physiological function of the receptor.

The receptor for herpes simplex virus exemplifies a situation of special interest from the point of view of future engineering of disease resistance. The viral receptor heparan sulfate is present on cell surfaces but body fluids also contain heparin and heparin-binding proteins, either of which can prevent binding of herpes simplex virus to cells (Spear et al, 1992). Hence spread of the virus is likely influenced by both immune response and the probability that the virus will be entrapped and inhibited from binding to cells by extracellular forms of the receptor (heparin or heparan sulfate). Similarly, soluble molecules of the CD4 receptor for human immunodeficiency virus, as well as fragments of the critical CD4 domains can inhibit infection (Smith et al, 1987). It has been suggested that a secreted receptor for avian leukosis virus might similarly be able to neutralize the virus (Bates et al, 1993).

\section{Penetration of a virus into the cell}

Penetration of a virus into the cells is usually an energy-dependent process that occurs almost instantly after attachment. As summarized by Roizman (1991), penetration can occur as (1) translocation of the entire virus particle across the cell membrane; (2) endocytosis resulting in accumulation of virus particles in- 


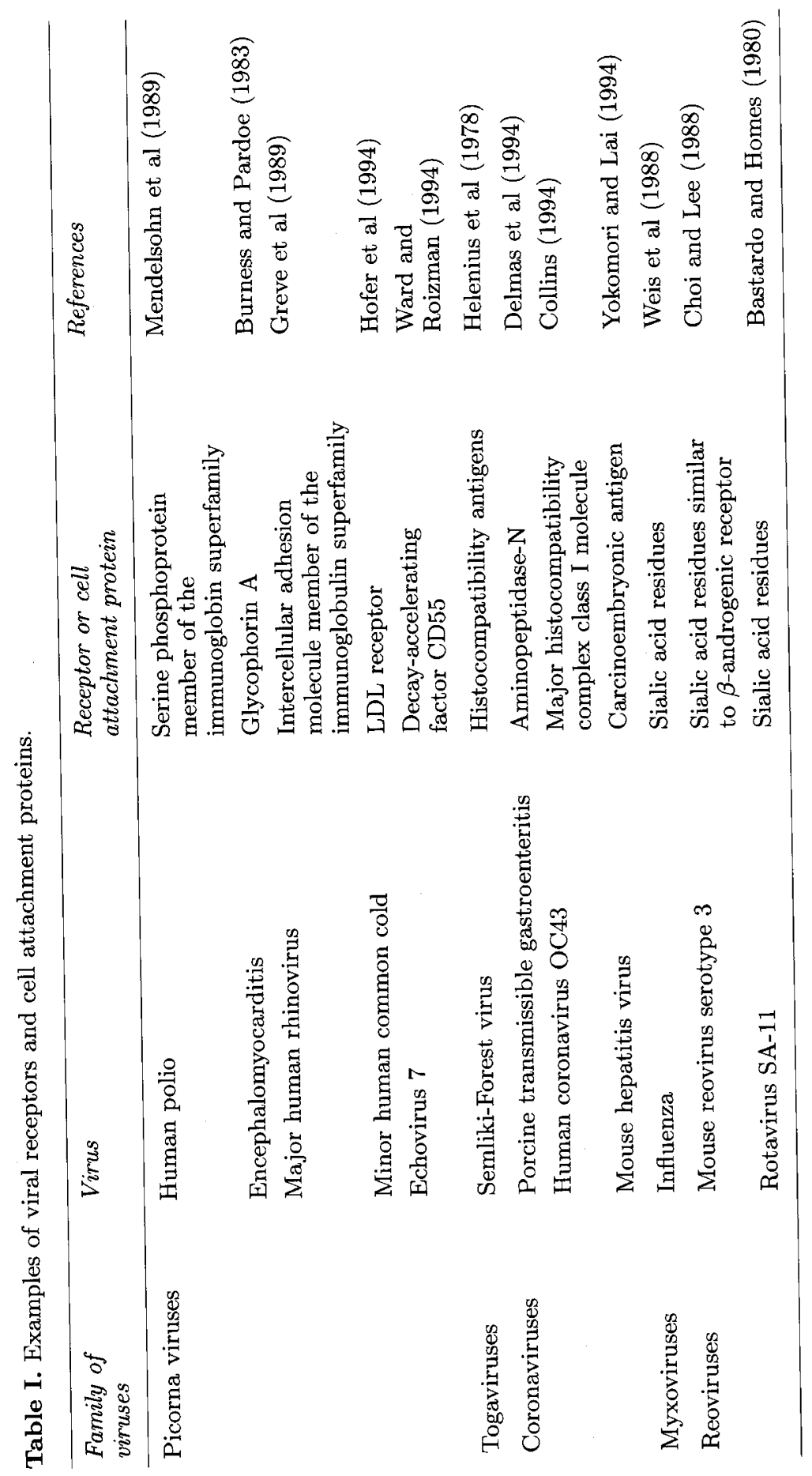




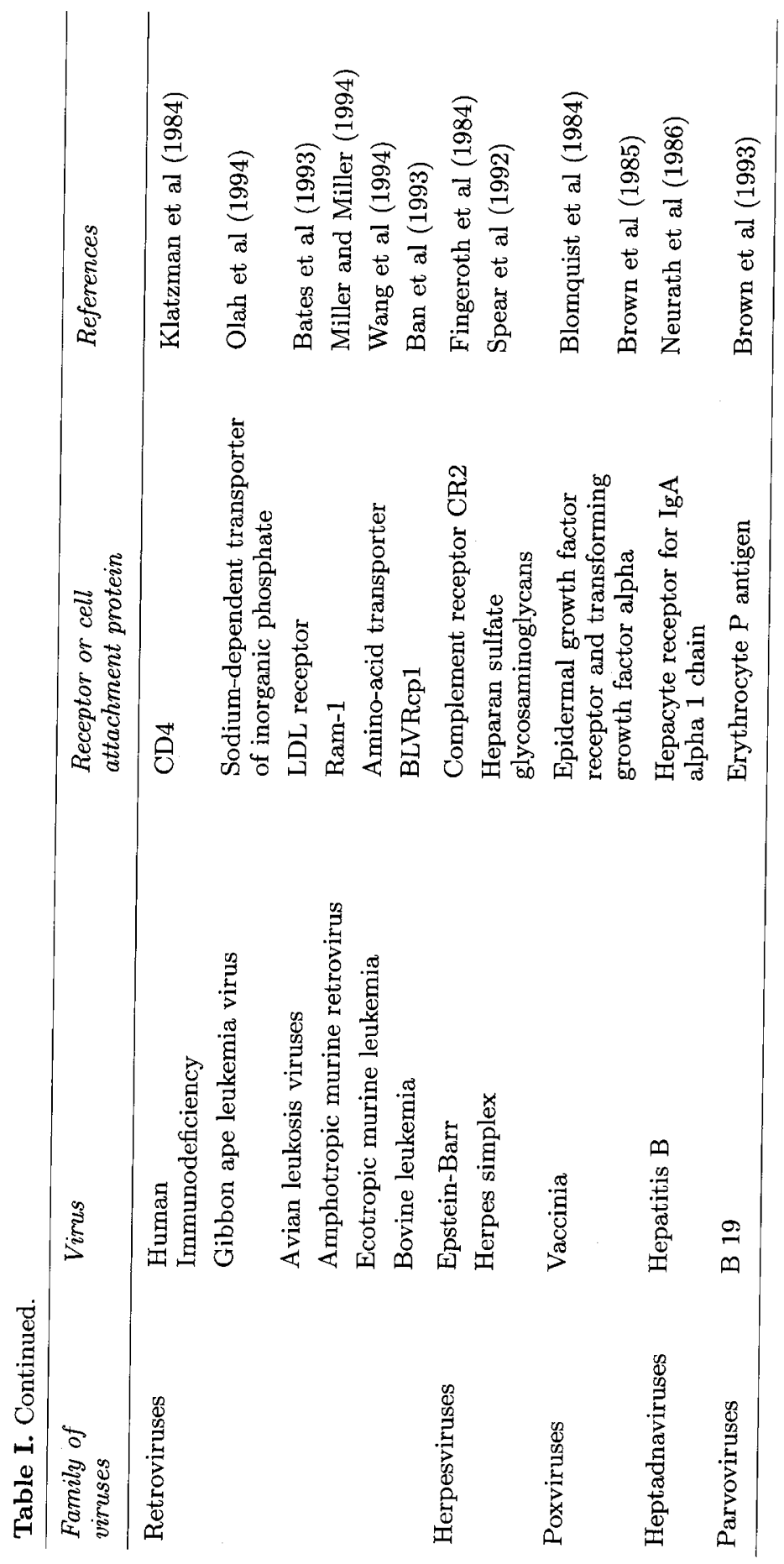


side cytoplasmatic vacuoles; or (3) fusion of the cell membrane with the virion envelope. Non-enveloped viruses penetrate host cells by the first two processes. Uncoating of the virus particle takes place after penetration. For some viruses, such as orthomyxoviruses and picorna viruses, divestiture of the protective envelope or capsid takes place upon their entry into cells. For others, such as herpes viruses, the capsid is transported along the cytoplasmic cytoskeleton into nuclear pores. With reoviruses, only a portion of the capsid is removed and the viral genome expresses all its functions even though it is never fully released from the capsid. While several genetic engineering strategies to prevent attachment of viruses to host cells can be devised and are proposed below, strategies to prevent penetration of viruses attached to cells are much less obvious.

\section{Virus multiplication}

Viruses use many strategies for replication leading to (1) encoding and organization of viral genomes, (2) expression of viral genes, (3) replication of viral genes, and (4) assembly and maturation of viral progeny. The key event in these processes is the synthesis of viral proteins. Regardless of its size, organization, or composition, a virus must present to the cell's protein synthesizing mechanisms an mRNA that the cell recognizes and translates.

The interaction between the viral cell attachment protein and host-cell receptors is the principal determinant of tropism, but there are other factors involved. For retroviruses and papovaviruses, cis-acting elements of the viral genome, gene enhancers, which are usually 50-100 bp in size and often repeated in tandem, stimulate transcription (Serfling et al, 1985). They may serve as an entry point for RNA polymerase II. Enhancers may be both cell-type-specific and cell-differentiationspecific, in that they function mainly in certain cell types (Tyler and Fields, 1991). For avian retroviruses, enhancer regions within the long terminal repeat (LTR) are an element of the viral genome that determines cell tropism of disease expression (Brown et al, 1988).

The cell imposes three constraints on the virus at the point of virus multiplication. (1) The cell may lack enzymes to synthesize mRNA off the viral RNA genome, or may lack enzymes to transcribe viral DNA. (2) Eukaryotic host cell protein-synthesis machinery translates only monocistronic messages and does not recognize internal initiation sites within mRNA. As a consequence the virus must synthesize either a separate mRNA for each gene or an mRNA encompassing a 'polyprotein' to be later cleaved. (3) The expression of viral proteins is in competition with cellular genes. Viruses evolved strategies that either confer competitive advantage to viral mRNA or abolish translation of cellular mRNAs.

The host range of a virus defines both the kinds of tissue or cells and animal species in which a virus can enter and multiply (Roizman, 1991). Receptors may be species specific. For example, the poliovirus receptor is only found on primate mammalian cells (McLaren et al, 1959). A tissue-specific receptor is exemplified by the CD4 receptor for the HIV virus, which is present only on T-lymphocytes (table I). Species-specifity of receptors is one of the components of non-host resistance that will be discussed in more detail below. 


\section{Other virus-cell interactions}

Infection with some viruses leads to inhibition of transcription of cellular proteincoding genes by host polymerase II, possibly through competition for transcription between cellular and viral genes. Herpes simplex virions contain a transcriptional activator complex (Post et al, 1981), while adenovirus provides a trans-acting E1A gene product responsible for increased polymerase activity after adenovirus infection (Nevins, 1986). Viruses can also induce or express new DNA-binding proteins. Thus a retrovirus encodes a homolog to cellular transcription factor AP-1 (Bohmann et al, 1987).

Splicing of viral mRNA precursors is accomplished by cellular enzymes. Influenza and retroviruses can regulate the extent of the splicing, adenovirus inhibits maturation of cellular mRNA, and influenza virus transcription complexes intervene in the host mRNA maturation (Knipe, 1991).

Many viral mRNAs are capped, in that they contain a single major initiation site near their $5^{\prime}$ end, and their translation is similar to that of host mRNA. However, inhibition of host mRNA translation provides the virus with increased availability of ribosomal units. Thus herpes simplex and poxvirus degrade cellular mRNA to decrease its translation (Inglis, 1982; Fenwick and McMenamin, 1984).

Other mechanisms include competition for the host translational apparatus by production of large amounts of viral mRNA, or viral mRNA with higher affinity to ribosomes than cellular mRNA (Knipe, 1991) and changes in the specificity of host translational apparatus; for example, extracts from poliovirus-infected cells translate poliovirus but not host mRNA (Rose et al, 1978).

Both RNA and DNA viruses cause inhibition of host-cell DNA synthesis (Knipe, 1991). Eukaryotic cell proteins contain signals that target them to a specific cell compartment or organelle. Viral proteins may also contain similar signals for their localization within the cell. Viral proteins make use of cellular chaperone proteins to secure their proper folding. Similarly, many post-translational modifications of viral proteins are performed by cellular enzymes. For example, tissue-specific proteases cleave specific proteins on the virion surface thus facilitating virion infectivity (Scheid and Choppin, 1988).

\section{Maintenance of viral DNA in the host cell and release of progeny virus}

There are two types of mechanism for maintaining viral DNA in the host cell: (1) virus DNA is integrated into the cellular genome, eg, in retroviruses; or (2) viral DNA is maintained as extrachromosomal circular molecule in the infected cell, eg, Epstein-Barr virus, or bovine papilloma virus. Viruses that persist in the body may cause damage, and prevention of persistence may be the next best defence if prevention of virus entry is impossible. Persistence is usually in differentiated cells that remain morphologically unchanged but may lose their differentiated or 'luxury' function, as well as their homeostasis. Persistent viruses can negatively influence host cells in two ways: (1) virus presence and replication causes damage resulting in a selective disadvantage; and (2) in such a way that the virus will gain an evolutionary advantage for which there will be selection pressure to maintain. Alternatively, some viruses undergo a latency stage in their life cycle that seems to cause little damage. 
Enveloped viruses move from infected cells either by budding through the plasma membrane or by secretion vesicles containing virus particles within the plasma membrane (Knipe, 1991). Non-enveloped viruses are mostly released by lysis of the cells but they can also leave without cell lysis as in Simian virus 40 (Norkin and Ouelette, 1976).

\section{Spread of virus through the host body}

To facilitate their survival and spread throughout the body, some viruses have evolved strategies to modulate the immune response of their host to their favor, a phenomenon recently reviewed by Fujinami (1994). Virus infection can lead to development of immune responses against the host's own tissues and viruses can also code for proteins, homologous to cellular proteins, that modify the host's immune response. For example, Epstein-Barr virus produces a BCRF1 protein similar to the interleukin IL-10 protein (a cytokine-inhibiting factor) that inhibits the production of IL-2 and IL-3, tumor necrosis factor, gamma interferon, and macrophage-granulocyte colony-stimulating factor. The herpes simplex virus-1 (HSV-1) but not HSV-2 can interfere with the complement system by producing a protein that acts as a receptor for the component of the complement cascade. Virus infections can also interfere directly with the major histocompatibility system (MHC). Cytomegalovirus encodes an MHC class I heavy-chain homolog that limits expression of the cellular class I molecules on cell surfaces and this may reduce killing of infected cells by host defences.

\section{EXISTING RESISTANCE MECHANISMS}

\section{Non-host resistance}

Most animal and plant species are resistant to the great majority of viruses. Nonhost resistance is the rule, susceptibility the exception. However, the nature of nonhost resistance is not sufficiently understood to fully explore the incompatibility between viruses and non-hosts (Wilson, 1993). Nevertheless, it is certain that we, as well as all animals, are "continuously bathed in a sea of microbes, yet harmed by a relatively few" (Oldstone, 1993). To coexist, viruses and their hosts have established, to a greater or lesser degree, an equilibrium. In general, normal coevolution of parasites and their hosts is from disoperation, through exploitation, to toleration and from facultative to obligatory mutualism, but genetic changes may also bring reversals to this process (Dobzhansky, 1959). None of the strategies for the creation of new, genetically engineered viral resistance mechanisms proposed in this article are derived from non-host resistance. Nevertheless, a brief discussion of the subject is included to stimulate further exploration of this widespread phenomenon as the possible basis for protection of livestock against viruses.

Some knowledge of non-host resistance mechanisms is emerging from experimentation with plant viruses that infect permissible but normally resistant cells by bypassing the resistance barrier (Dawson and Hilf, 1992). Viral host range is determined by interactions between existing viral gene products and corresponding host components. Because of the obligately parasitic nature of viruses, viral host range is 
not determined by a particular gene product that enables the virus to overcome host defences but by a 'fit' between viral gene product and certain gene products of the host. There are two general prerequisites for successful infection: (1) Presence of all conditions necessary for viral infection. Absence of the conditions results in 'passive resistance mechanisms' in plants, that tend to be recessive or incompletely dominant. (2) Absence of successful host defences. Adaptation mechanisms of viruses that enable them to infect potential hosts protected by non-host mechanisms may include an ability to overcome a host block by a mutation or recombination with another virus, or acquisition by the virus of capabilities formerly provided by the hosts that are not available in resistant plants. A virus can capture such genetic information from the host.

\section{Non-immune mechanisms}

There are many mechanisms of resistance to viral diseases. For our purposes, emphasis will be placed on non-immune mechanisms. Of particular interest in this review are those mechanisms that prevent the entry of viruses into host cells. Viral receptors can be variable so that some alleles of the receptor may make the potential host resistant to viral infection. However, it is only rarely that resistance to infection is observed in otherwise susceptible host species. This indicates that during virushost coevolution, viruses tend to utilize evolutionarily stable molecules as receptors.

Resistance to infection by parvovirus B 19 in some humans is due to lack of a specific virus receptor. People who do not have the erythrocyte $\mathrm{P}$ antigen parvovirus receptor (Brown et al, 1993) are naturally resistant to the virus (Brown et al, 1994). Another example is resistance to coronaviruses in mice. A monomeric protein has been identified as a receptor for mouse hepatitis virus on intestinal and liver cells. The presence of this receptor appears to be the principal determinant of susceptibility to infection (Boyle et al, 1987). Similar variation in viral receptors is observed in genetic resistance to avian leukosis virus (ALV) infection in chickens (Payne, 1985). The ALV receptors, which belong to the family of receptors for LDL (Bates et al, 1993), include recessive alleles that do not allow viral entry into potential host cells and render some chickens resistant to the virus. The receptor for subgroup A ALV was shown to map to TVA*S known as the dominant gene for susceptibility to subgroup A virus (Bates et al, 1994).

Susceptibility of cells to infection needs to be distinguished from permissiveness, which can be defined as the ability of a cell to support viral replication. For example, chick cells are not susceptible to poliovirus but are permissive to its replication following their transfection with poliovirus RNA (Roizman, 1991). Such cells are potential hosts for a virus, providing a mutation provides means for the virus to enter the cells.

In laboratory mice, alleles at the $F v-4$ locus determine susceptibility to infection with ecotropic murine leukemia viruses and the resistance is dominant in heterozygous mice (Ikeda and Odaka, 1983). A viral protein gp70 normally interacts with the viral receptors on cells. However, in resistant mice, the specific receptor on cell membranes seems already bound by the gp70 whose production is controlled by the mouse $F V-4^{\mathrm{r}}$ resistant allele. This system is similar to that in chickens, where the endogenous retroviral gene $e v$-6, expressing the subgroup $\mathrm{E}$ endogenous viral 
envelope also controls resistance to infection by subgroup E virus (Robinson et al, 1981).

Resistance of mice to certain strains of influenza virus is a dominant trait associated with the allele $M x$ on chromosome 16 (Staehli et al, 1986). The resistance is mediated by action of alpha- and beta-interferons that induce $\mathrm{Mx}$ protein expression which inhibits synthesis of viral mRNA (Krug et al, 1985).

A recent review of natural, 'preimmune' resistance loci in mice (Malo and Skamene, 1994) includes genes controlling resistance to influenza virus, cytomegalovirus, ecromelia, Friend leukemia virus, mink cell focus-forming virus, Moloney leukemia, radiation leukemia, and Rous sarcoma virus. The resistance genes represent a variety of mechanisms that do not involve viral receptors. For example, the $C m v 1$ gene, associated with resistance to cytomegalovirus, appears to control host responses mediated by natural killer and inflammatory response cells. Similarly, the resistance loci in Friend leukemia control the susceptibility of target cells to viral replication.

\section{Immune mechanisms}

It is not the purpose of this review to provide a detailed account of immune mechanisms that protect against virus infection. The brief text below will give only a general outline of immune responses and examples of how the system may be influenced by viruses.

Acquired immune responses involve phagocytic, humoral and cell-mediated systems. Only the cell-mediated immune response that is especially effective against cells containing actively replicating virus and, as a rule, is the most important defence against viral infections will be discussed briefly. The cellular immune system becomes sensitized to viral infection only after viral proteins are degraded to short linear peptide epitopes that become complexed with class I or II major histocompatibility complex proteins. The resulting complexes are transported to cell surface, where they are presented as 'non-self' entities to T-lymphocytes. If the viral antigen has not previously encountered the T-cell repertoire of the host, the initial antigen-specific activation event requires appearance of MHC-peptide complexes on antigen-presenting cells. But if activated T-cells, previously sensitized to the viral epitopes are available, then a broader class of antigen-presenting cells can be targeted for clearance by cytotoxic $\mathrm{T}$ cells. In both events, the ability to discriminate self molecules from the viral epitopes depends on the presentation of the non-self peptide to T-cells in specific peptide-binding grooves of the MHC molecules on antigen-presenting cells.

McFadden and Kane (1994) summarized how DNA viruses perturb the MHC and alter immune recognition. A number of gene products of DNA viruses have been identified as directly affecting MHC expression or antigen presentation, whereas RNA viruses interact with MHC by indirect mechanisms. Most DNA viruses are able to modulate cellular immunity. It seems that many viral gene products remain to be identified among the open reading frames of as yet unknown function that exists in these viruses. Besides a trivial strategy of hiding DNA molecules in cells, such as neurons that lack MHC surface molecules, viruses can modify MHC expression directly within cells or indirectly at the level of cytokine regulation. 
There is now evidence that viruses can combat antiviral effector $\mathrm{T}$ cells directly by blocking their antiviral activity (Bertoletti et al, 1994). In humans infected with HIV-1 and hepatitis B viruses, naturally occurring variants of epitopes recognized by cytotoxic $\mathrm{T}$ lymphocytes may act as antagonists in vivo because the corresponding peptides prevent a cytotoxic $\mathrm{T}$ cell response. Although exactly how the antagonists function is not known, it is evident that the presence of these antagonists prevents the $\mathrm{T}$ cell from performing its function.

Endogenous viruses represent a separate phenomenon with regards to the immune system. As a rule, the host is completely immunologically tolerant to endogenous viruses. However, antibodies against endogenous retroviruses were found in mice (Miyazawa et al, 1987). How the immune system makes antibodies against endogenous retroviral gene products is unknown but this ability may relate to the expression of such genes after the establishment of immunological tolerance to endogenous retroviral antigens expressed earlier in life (Miyazawa and Fujisawa, 1994). A similar delay in expression of the endogenous viral gene ev-6 has been described in chickens (Crittenden, 1991) and may serve as a model for construction of similar 'self-vaccinating' transgenes in the future.

\section{Pathogen-mediated resistance}

Given the potential benefits that can be derived from the use by the host of parts of a pathogen's genome to induce resistance, the paucity of pathogen-mediated resistance mechanisms in nature is surprising. The situation begs the question whether evolution exhausted all such possibilities in the development of host defences. Why did certain mechanisms develop and others not? A reason for the absence or rare occurrence of pathogen-mediated defence mechanisms may be that they encompass some disadvantage for the host.

One example in which a viral genome has become an integral part of the host are endogenous proviruses found in germ cells of all vertebrates. For example, in the laboratory mouse endogenous proviruses occupy more than $0.5 \%$ of the cellular DNA (Pincus et al, 1992). In the genomes of chickens, there are several families of retrovirus-related permanent insertions. In the most thoroughly studied family of endogenous viral genes, there are more than 20 endogenous proviruses in various parts of the genome (Crittenden, 1991). The presence of some of these proviruses may interfere in the spread of the generally non-pathogenic endogenous virus produced by other such proviruses. However, the endogenous proviruses do not protect the host against infection with similar but more harmful, pathogenic exogenous viruses. On the contrary, the antigenic similarity between the products of the endogenous proviruses and the exogenous viral antigens reduces the ability of birds with certain types of these proviruses to mount an immune response against the exogenous virus (Crittenden et al, 1984; Gavora et al, 1995b). A possible reason why other endogenous proviral sequences did not evolve as resistance mechanisms is that their expression may adversely affect important physiological processes of the host (Gavora et al, 1995a,b) and reduce the ability of the host to resist the exogenous analogues of the proviruses. 


\section{CONVENTIONAL METHODS FOR IMPROVEMENT OF RESISTANCE AND POSSIBLE ADVANTAGES OF GENETICALLY ENGINEERED RESISTANCE MECHANISMS}

Genetic variation is a prime prerequisite for genetic change by selection. As a general rule, genetic variation exists in the ability of livestock to tolerate infectious diseases. And it was this variation that allowed populations of domestic animals and birds to survive under continuous exposure to rapidly evolving disease agents. Before domestication, disease resistance of today's livestock species was influenced by natural selection and the current status of variable resistance to multiple disease agents can be considered to be the result of a response to the selection pressure of multiple pathogens.

As a consequence of domestication, a significant new element that entered this evolutionary system was artificial selection for characters that benefit humans as users of livestock. Simultaneously, housing conditions evolved towards increased concentration of animals and birds and thus provided opportunities for spread of pathogens. Improved disease prevention and control measures now provide some compensation for the larger population sizes used in current production systems.

Selection for disease resistance plays a relatively minor but increasingly important role in livestock improvement. The choice of selection criteria and the emphasis they receive in the context of total selection pressure available to a practical breeder are decided by market demands and economic considerations. Disease resistance traits receive attention from the breeders mainly when a specific disease is a major cause of economic loss.

Although in most instances existing genetic variation provides an adequate basis for resistance selection, selection may not always be practised. Such selection is expensive because the expression of resistance traits requires exposure of selection candidates or their relatives to the disease agent. This is why industries prefer to look for indirect selection techniques that do not require pathogen challenge. Recent developments in gene mapping provide good prospects for progress in this direction. Indirect selection for resistance to the herpesvirus of Marek's disease in chickens, by increasing the frequency of the 'resistant' major histocompatibility haplotypes, is one example of such a technique. It has been practised by most of the world's poultry breeding companies over the past two decades (Gavora, 1990).

Conventional procedures for direct and indirect selection for disease resistance will in the foreseeable future be the main route for genetic improvement of disease resistance. One disadvantage of their application is the general absence, with rare exceptions mentioned above, of genetic variation in resistance to infection. Thus genetic improvements in disease resistance by conventional means lead mostly to better resistance of livestock to disease development - a situation where the organism becomes infected but tolerates the pathogen and reduces its ill effects.

Hence development of new genetic mechanisms that prevent entry of a pathogen into the host, or otherwise substantially improve the position of the host in the pathogen-host interaction is justified. While conventional selection leads to quantitative improvement of resistance, the new mechanisms would represent a qualitative change that, at least in some instances, will justify the large effort and cost. The expenses will be further justified if the new, engineered mechanism proves 
to be stable and remains effective despite evolution of the pathogen and functions without harmful effects on the animal's production capacity. Improvement in the welfare of the modified livestock will be an automatic, additional benefit.

\section{In crops}

Despite large differences between animals and plants, sufficient similarities exist in their resistance mechanisms to justify examination of the situation in plants with regards to genetic engineering of viral resistance. For example, normal virus replication requires a subtle balance of virus and host coded proteins, present in critical relative concentrations at specific times and locations. Therefore, Wilson (1993) suggests that any unregulated superimposition of protein or nucleic acid species interacting with the virus can result in plants in an apparently virusresistant phenotype. The results from experimentation with animal cells into which a viral gene was inserted indicate that a similar situation may also exist in animals (Gavora et al, 1994).

The idea that viral components contained in plants might interfere with virus infection was first proposed well before gene transfer techniques became available (Hamilton, 1980) and the concept of pathogen-derived resistance was first put forward in a formal statement by Sanford and Johnston (1985). There are several approaches to the introduction of disease resistance by gene transfer in plants (Fitchen and Beachy, 1993). They include transfers of segments of viral genome encoding capsid or coat proteins, viral sequences encoding proteins that may be subunits of viral replicase, sequences incapable of encoding proteins, entire genomes of defective, interfering viruses, and complete genomes of mild virus strains. The transgenes may act on initiation of infection, replication of virus, spread of infection throughout the plant, and symptom development. The level of protection derived from the transgene ranges from low to high and its breadth of host range from broad to narrow. The available data are not sufficient to firmly establish the molecular mechanisms of the protection. In general, although a viral sequence may confer resistance in one virus-host system, an analogous sequence from a different virus in another virus-host system may not be effective.

\section{Protection conferred by sequences encoding viral coat proteins}

The conceptual simplicity of the approach and availability of virus coat gene sequences facilitated broad implementation of this strategy. Fichten and Beachy (1993) list 19 published examples of this approach. It is unlikely that a single mechanism accounts for the observed resistance of the transgenic plants but regardless of the mode of the transgene action, resistance results from a block in an early event in the infection process (Fichten and Beachy, 1993). In resistance to some viruses other than tobacco mosaic, it seems that accumulation of the coat protein transgene RNA, rather than the virus coat protein itself is responsible for resistance. Resistance has been observed even in plants that transcribed a translation-incompetent coat protein mRNA (Kawchuk et al, 1991; De Haan et al, 1992). It seems that even in the absence of understanding of its mechanism, the strategy can be extended to other plant species and viruses. 


\section{Protection by sequences encoding replicase-related proteins}

Replicase-mediated resistance was first demonstrated against tobacco mosaic virus (Golemboski et al, 1990). The number of initially infected cells in transgenic and non-transgenic plants was the same but virus replication was markedly reduced in cells of the transgenic plants. Replication of the virus was severely impeded and little or no systemic spread of the virus occurred (Carr and Zaitlin, 1991).

\section{Protection by the accumulation of RNA}

Plants were protected by RNA-mediated resistance to a degree comparable to protein-mediated resistance. Transgenic tobacco plants, carrying a translationally defective tomato spotted wilt virus nucleocapsid gene exhibited resistance similar to that in experiments with translationally competent gene constructs (De Haan et al, 1992). Other examples include potato plants with constructs producing sense and antisense transcripts of potato leafroll virus (Kawchuk et al, 1991) and tobacco plants and similar transcripts of tobacco mosaic virus (Powell et al, 1989).

\section{Protection by transgene copies of mild strains, satellites and satellite RNAs, and defective interfering viruses}

Transgenic tobacco plants carrying cDNA of a mild strain of tobacco mosaic virus developed only mild symptoms when challenged with severe strains of the virus (Yamaya et al, 1988). Transgenic plants expressing cloned copies of different virus satellites or satellite RNAs have also been produced. For example, in experiments with tobacco ringspot virus, such transgenic plants exhibited delayed development of symptoms (Gerlach et al, 1987). Nevertheless, this approach does not seem desirable because the transgenes may produce active pathogens by recombination or a pathogenic mixture. Also, transgene components may recombine with another virus, thus extending its host range or virulence (Fitchen and Beachy, 1993).

The identification of a variety of disease resistance $(R)$ genes is expected to facilitate identification and introgression of new resistance from wild species into new plant varieties. It is well known that a new resistant plant variety developed over a long time and with great effort is often overcome by a new pathogenic race - an immensely wasteful situation. Such breakdown of resistance is much less likely in varietal mixtures that carry an array of different $R$ genes. Once different $R$ genes are cloned, varieties can be produced that consist of mixtures of lines differing only in the $R$ gene allele they carry (Staskawitz et al, 1995). For genetically engineered resistance, pathogen-inducible promoters, such as the prpl-1 promoter in potato (Martini et al, 1993) may be the most advantageous as they induce the 'resistance' peptide(s) only in cells that are being challenged by a compatible pathogen (De Wit, 1992).

\section{In livestock}

The extent of the research effort to genetically engineer new resistance mechanisms in animals is much smaller than that in plants and available data on the subject are reviewed below. 


\section{Pathogen-mediated resistance}

The first successful introduction of pathogen-mediated resistance to disease in animals was reported by Salter and Crittenden (1989). They produced several lines of chickens, each with an insert of a recombinant avian leukosis retroviral genome at a different locus within the host genome. The transgenic birds that expressed only the viral envelope coding region of the recombinant genome were shown to be resistant to the corresponding subgroup of the avian leukosis virus (Salter and Crittenden, 1989; Gavora et al, 1995a), due to a blockage of virus receptors by the viral envelope proteins.

Another introduction of a new virus resistance mechanism into a livestock host was attempted by Clements et al (1994). They produced sheep carrying transgenes expressing the envelope genes of visna virus, under the control of the visna virus LTR. Visna virus is a prototype of a family of ovine lentiviruses that cause encephalitis, pneumonia, and arthritis in sheep worldwide. In three transgenic lambs that expressed the visna virus envelope glycoproteins, the transgene had no obvious deleterious effect.

Inhibition of virus replication in mammalian cells has been demonstrated in humans with wild-type (Tsunetsugu-Yakota et al, 1992) and mutant (Owens et al, 1991; Hope et al, 1992) forms of replication-associated proteins encoded by HIV and adeno-associated viruses. The mutated trans-dominant forms of the adenoassociated virus Rep78 protein bind to the origin of viral replication, thus preventing the binding of wild-type protein, while trans-dominant mutant forms of the HIV Rev protein associated with the wild-type Rev protein, form nonfunctional complexes (Owens et al, 1991).

Expression under the control of metallothionein of a single glycoprotein $D$ gene from herpes simplex virus (HSV-1) rendered cells resistant to infection by HSV but not by other viruses (Johnson and Spear, 1989). The mechanism of this resistance is not known but it seems likely that $D$ interacts with a cell surface component required for viral penetration.

In an attempt to introduce resistance to bovine rotavirus that causes calf diarrhea and results in large economic losses, two genes that code for rotavirus capsid proteins, implicated in early virus-host cell interactions, were transferred into the genomes of susceptible cells in culture and, one of the genes, also into genomes of laboratory mice (Gavora et al, 1994). The transgenes produced mRNA of the relevant viral genes but no corresponding protein was detected either in the cells or in the mice. Nevertheless, several of the transformed cell lines showed significantly increased resistance to bovine rotavirus (Gavora et al, 1994), while no increase in the resistance of four similarly transformed lines of mice was detected following challenge of pups shortly after birth with the virus (JS Gavora, unpublished results).

\section{Antisense RNA}

Although not yet tested in vivo, the use of antisense RNA to combat viruses has received attention by researchers and presents another possible avenue for the construction of new resistance mechanisms. The possibilities of inhibiting retroviral replication by antisense molecules before its integration into a host chromosome has 
been demonstrated (To and Neiman, 1992). To block viral integration, antisense sequences can be designed to target regions essential in the synthesis of viral DNA intermediates or viral integration. Replication of a recombinant avian retrovirus, carrying a neomycin resistance gene neor in the antisense orientation was blocked when cells expressed high levels of neor RNA molecules in the sense orientation, suggesting that antisense RNA inhibition may be a useful strategy for inhibition of retroviral infections (To et al, 1986). It was hypothesized that when sequences immediately upstream of the polypurine tract are hybridized to antisense molecules, RNase $\mathrm{H}$ failed to process the RNA sequences in the polypurine tract into a functional primer for the synthesis of plus-strand DNA (To and Neiman, 1992). They suggested that an antisense segment in that region can be defined for use in a large number of pathogenic retroviruses. These experiments also showed that constructs expressing the antisense RNAs can be delivered by replication-competent retroviral vectors to host cells in culture, thereby immunizing the host cells against superinfection with different retroviruses.

The advantage of the antisense RNA approach may be that only about 15 basepairs are needed to bind the antisense RNA with absolute precision to a unique mRNA and intensive research is now under way to develop antisense therapeutics (Bradley et al, 1992). Even though the mechanism will not prevent viral entry into host cells, it may prevent integration of the viral genome in the host chromosome.

Catalytic RNAs, known as ribozymes, are not rare in nature and it is possible to engineer an intron that can repeatedly perform the first chemical step in the splicing process (Parker et al, 1992). Ribozymes have been shown to cleave target RNA and to inhibit mRNA transcript activity (Edington and Nelson, 1992). The principal advantage of ribozymes is their ability to cleave and thus inactivate multiple targets. Even though ribozyme-mediated gene inhibition involves a mechanism (target cleavage) different from that of bacterial antisense RNAs, many of the essential steps of the two mechanisms are identical. Ribozymes were shown to successfully inhibit gene expression in Xenopus oocytes in tissue culture (Cotten and Birnstiel, 1989) and may be another possible approach to the engineering of new disease resistance mechanisms for livestock.

\section{Transfer of resistance genes from another species}

As was mentioned above, the murine $\mathrm{Mx} 1$ is a protein with activity against influenza virus. Garber et al (1991) inserted cDNA encoding this protein into chicken embryo fibroblasts through the use of a replication-competent avian retroviral vector. Cells infected with the vector were resistant to infection with avian, as well as human influenza viruses but susceptible to enveloped RNA viruses.

\section{Biological costs of and risks associated with genetic engineering}

Conventional methods of genetic improvement are rather forgiving in the sense that they induce gradual changes and provide time for the breeder to correct disturbances in biological equilibria that might be harmful to the animals. Gene transfer, on the other hand, may induce dramatic, undesirable changes that will disturb development or physiological functions that are difficult to correct. However, 
new technological developments, such as homologous recombination and use of embryonic stem cells for gene transfer will likely reduce the risks.

Given the extent of work on transfer of disease resistance-inducing genes in both plants and animals, surprisingly little research has been done on the possible physiological consequences of adding such new genes to cells. Consequences of transgenes have been demonstrated in plants by Hilder and Gatehouse (1991). They studied lines of transgenic tobacco containing a cowpea trypsin inhibitor gene construct which expressed the transgene at various levels and plants that possessed, but did not express, the gene. Small, but in some instances, significant differences between the transgenic and non-transformed plants were found in various parameters but there was no additional difference between plants that expressed the transgene and those that did not. They concluded that although the transformation may have some small effects on non-targeted phenotypic characteristics, the expression of the transgene at high levels imposed no additional yield penalty on the plants.

Negative genetic correlations between disease resistance and production traits have been reported (eg, Gavora, 1990) but their basis as to linkage or pleiotropy is not clearly established. Design of genetically engineered resistance mechanisms may have to take possibility of such negative correlations with production traits into consideration.

As mentioned above, a transgene that successfully induced resistance of chickens to avian leukosis retrovirus subgroup A in chickens (Salter and Crittenden, 1989) was shown to result in a sizeable reduction of egg production rate (Gavora et al, 1995a). It was suggested that the reduced ovulation rate was due to interference of the viral envelope protein produced by the transgene with the attachment of the virus to host cells and also with transport of lipids into the developing egg yolk, since the virus uses an LDL receptor for entry into host cells (Bates et al, 1993). On the other hand, a transgene containing a gene for a capsid protein of bovine rotavirus in laboratory mice (Gavora et al, 1994) was not associated with any significant effects on their growth and reproductive performance ( $\mathrm{J}$ Nagai and JS Gavora, unpublished results). Hence, significant 'biological costs' may not always accompany insertion of transgenes but they need to be considered in strategies for genetic engineering of new resistance mechanisms.

Reports on work on assessment of risks involved in the production of varieties with new, genetically engineered resistance are only available for plants. Transgenic plants expressing viral pathogen-derived DNA sequences have been considered sites for hyperevolution of viruses through recombination of a mild or defective viral genome with the transgene (De Zoetten, 1991). However, there is no experimental evidence to confirm this supposition. On the contrary, evidence against this type of event exists through one to up to eight viral passages, even though heteroincapsidation of viral RNA by transgenically expressed viral coat proteins has been observed (Wilson, 1993).

The danger that transgenic crops may generate new viruses and diseases has been assessed by Falk and Bruening (1994). They provide evidence that genomic recombination was observed when transgenic tobacco plants expressing a segment of cowpea chlorotic mottle virus genomic RNA were inoculated with a mutant of the same virus that contained a deletion (Greene and Allison, 1994). The important question is whether such recombination can produce dangerous new 
viruses. RNA-RNA recombination has indeed been demonstrated for four groups of RNA plant viruses. The recombination occurs between closely related RNA molecules, possibly at sites of similar RNA structure. Under usual crop production circumstances, opportunities exist for genetic interaction between plant viruses in mixed virus infections. Since both crop plants and weeds may be present in a field, recombinations between a virus that cannot infect a plant and one that can, do not have a zero probability. Nevertheless, mixed infections rarely result in new plant pathogenic viruses. Instead, new viral diseases are usually due to minor variants of already known viruses. Generally, however, existing viruses are stable, having to fit hosts that evolve only slowly. Falk and Bruening (1994) believe it is unlikely that recombinations between transgene RNA and viral genomic RNA will occur at greater frequencies than the recombinations already occurring between virus genomic RNAs in natural infections.

In the past, development of resistant plants by traditional breeding fostered the emergence of virulent virus strains (Dawson and Hilf, 1992) but the cost of this phenomenon is much less than the cost of abandoning plant breeding. Similarly, the benefits of engineered plant resistance genes far outweigh the vanishingly small risk of creating harmful new viruses in significant excess over those being created by natural processes (Falk and Bruening, 1994).

In mice, endogenous proviruses are known to recombine with exogenous viral sequences to give rise to novel viruses with unique properties (Pincus et al, 1992). Similar recombinants between exogenous and endogenous avian retroviruses had been produced in vitro and used as transgenes to induce resistance to the exogenous retrovirus in chickens (Salter and Crittenden, 1989).

Endogenous viral genes may be regarded as prototypes of transgenes in animals. Early evidence that Rous sarcoma virus recombined with envelope protein of endogenous avian virus was provided by Hanafusa et al (1970). Recently, an env gene related to endogenous viral gene was found on the exogenous avian leukosis virus subgroup $\mathrm{J}$ (Bai et al, 1995). There is also evidence that the alv6 transgene that expresses the avian leukosis virus subgroup $A$ envelope can recombine with endogenous virus from gene ev21 to produce subgroup A infectious virus (LB Crittenden, personal communication).

Until more results become available in animals, we could assume that a situation similar to that described above for plants will also exist in livestock. However, it is imperative to keep the possible risks in mind in designing strategies for induction of resistance by genetic engineering and to experimentally assess the recombinations, if any, between transgenes and existing viruses in farm animals and birds.

An example of an increase in the virulence of an animal virus that may be associated with improved resistance of the host by vaccination and genetic means is the emergence of highly virulent Marek's disease herpesviruses in chickens (Witter, 1988). The viruses may have emerged as a consequence of vaccination and conventional selection for resistance that included efforts to increase the frequency of major histocompatibility haplotypes associated with such resistance. Genetically engineered resistance may provide a more stable solution to the Marek's disease problem. Conventional breeding and vaccination improved survival of chickens infected by Marek's disease virus. However, the virus continues to be present in vaccinated birds so there are ample opportunities for its mutations towards higher 
virulence. A genetically engineered mechanism that would prevent the entry of the virus into the host cells would reduce the size of the viral population and thus reduce the possibility of such viral evolution. Unfortunately emergence of viral mutations to overcome the genetically engineered barrier to virus entry would be difficult to eliminate.

It seems that the arguments used by plant breeders in favor of continuing research toward new, engineered resistance genes should also be valid for livestock. A necessary prerequisite for this development has to be an adequate system of controls and thorough testing of the engineered livestock.

\section{PREREQUISITES AND STRATEGIES FOR GENETIC ENGINEERING OF DISEASE RESISTANCE IN LIVESTOCK}

As mentioned above, any introduction of new genetic material into a cell carries with it a risk of disrupting cell functions. This risk has to be kept in mind in the design of new resistance mechanisms. It may be possible to minimize such risks on the basis of a thorough understanding of the physiology of virus-infected animals and interactions between the virus and the host.

Another, no less important aspect of the design of new resistance mechanisms is their long-term stability. The new mechanism may become ineffective through evolution of the virus which will overcome the resistance provided by the transgene. Evolution of pathogen virulence genes that overcame resistance induced by conventional breeding is well known and documented in plants (Flor, 1956; Wilson, 1993), and a possible instance of a similar phenomenon observed with Marek's disease herpesvirus in chickens was mentioned above.

The design of new mechanisms and strategies of disease resistance to be introduced into livestock by genetic engineering techniques is a search for mechanisms that did not, for whatever reason, develop by evolution. Unlike most of the mechanisms of defence of the hosts against viruses that resulted in virus tolerance by the host, the ideal goal of the new, engineered mechanisms should be prevention of viral entry into host cells. It may be easier to develop new resistance strategies for viruses which depend for most of their functions on the host cell than for those that provide for the functions in their genome. New techniques of molecular and cell biology allow transfers of genes between species, taxonomic genera and even kingdoms so that we are no longer limited by the constraints of sexual compatibility.

Recent progress in the development of techniques of homologous recombination, together with the use of embryonic stem cells for gene transfer provide good prospects for progress in this area of research (First et al, 1994). While the use of both of these techniques is now routine in laboratory mice, their application in animal agriculture is hampered by the unavailability of a reliable technique for the production of embryonic stem cells in any of the livestock species. Nevertheless, given the high level of interest and scientific activity in this area in several countries, it is likely only a matter of time before embryonic stem cells will become available for introduction of new genetic information into the genomes of farm animals and birds.

Homologous recombination and use of embryonic stem cells will allow insertion of a transgene in a predetermined location in the genome. In the case of gene 
constructs designed to induce new resistance mechanisms, the insertion will likely be targeted into a 'neutral' region of the genome, to minimize the potential disruption of important genomic functions. After successful insertion, it will be possible to test the transformed embryonic stem cells in culture for the expression of the transgene, its stability and, as much as possible, its undesirable effects on the cells. Preliminary testing in cell culture for resistance to the pathogen in question will be also possible. Only the embryonic cell lines that will meet criteria of acceptability in the above tests will be used for the introduction into developing embryos with the goal of producing disease resistant transgenic individuals. It is anticipated that the protocol will make the introduction of new disease resistance mechanisms into livestock less expensive. The approach will also be less risky as the dangers of disruption of important genetic mechanisms by the transgene insertion will be reduced by gene targeting. Moreover, the reduction of such risks will make the research more acceptable for both livestock producers and the general public. Unfortunately, the use of advanced techniques of gene transfer will likely be limited to developed countries.

Because of their relative simplicity and small size, the genomes of viruses are generally better understood than those of host cells. Many viral genomes have been sequenced and it is generally easy to obtain the necessary sequence information for viral genes that are candidates for inclusion into potential resistance-inducing transgene constructs.

The general principles for the design of new resistance mechanisms and the new defence strategies can be summarized as follows. The most useful would be mechanisms based on an element common to the life cycle of multiple viruses thus inducing resistance simultaneously to more than one virus. The new mechanisms should be designed to minimize their biological and financial costs. Targeting of transgenes into 'neutral' regions of the genome may be one such strategy. The 'neutrality' of such regions can be tested by inserts of non-functional genes. The regions proven to be 'neutral' would be subsequently used for inserts of resistance genes. Ideally the functioning of the new mechanisms should be triggered by the presence of the inducing virus, otherwise the mechanism should remain 'silent'. This type of mechanism would minimize its biological cost to the host.

Despite preliminary testing of transformed cells in culture, it will be essential to subject livestock carrying the resistance transgenes to a series of rigorous tests (Smith et al, 1987; Gama et al, 1992). The tests need to prove the genetic potential of the new stock for economically important production traits, general viability, as well as resistance against the disease for which the transgene was designed. In instances of slight impairment of the production capacity of the transgenic, compared to the original stock, decisions on the practical usefulness of the modified animals will depend on comparison of the economic benefit derived from the transgene against the cost of the animals' reduced production performance. In this context, the prevalence of the pathogen in question and the damage it causes in the production areas for which the resistant animals are intended will be, no doubt, important considerations.

Based on considerations of the viral life cycle, and natural and genetically engineered resistance mechanisms that were already tested, several possible strategies can be proposed and are listed below according to stages of viral life cycle. The 
strategies are identified in a general manner, without reference to specific viruses. Therefore, no description of details of their design and implementation is attempted. The aim of this list is to stimulate further activity in this area by outlining the opportunities that exist. Without a doubt, a new resistance mechanism that would prevent viral attachment and penetration into host cells represents the most desirable approach. Those acting on subsequent phases of viral life cycle are less desirable and should be considered if prevention of viral attachment and penetration is impossible.

\section{Viral attachment and penetration into host cell}

\section{Transgenes that}

- produce viral antireceptor (virion surface) proteins to block cellular receptors;

- produce soluble receptors or their components to block virion surface proteins and prevent their interaction with cellular receptors;

- replace host receptor genes by a modified form that is able to perform the receptor's physiological function but does not allow the attachment of the virus;

- produce substances that interfere with viral penetration into host cells.

\section{Multiplication of the virus and release of its progeny}

\section{Transgenes that}

- induce antisense RNA to a part of the viral genome crucial for virus multiplication;

- cause multiplication and accumulation of viral or modified viral RNA in host cells;

- disturb viral replicase or its function;

- produce ribozymes attacking viral RNA;

- produce a defective viral protein that competes with the normal one to produce a high proportion of non-infectious virions.

\section{Viral latency}

Transgenes that

- induce and maintain a latent state of the virus;

- do not allow activation of a virus from its natural latent state.

\section{Spread of virus through the host's body}

Transgenes that

- protect against perturbances of the host's immune system;

- produce the vaccinating antigen only after the immune system is fully developed (self-vaccinating transgenes). 


\section{CONCLUSIONS}

Enormous variability of viral types in their strategies for life and survival will likely make it difficult to engineer generalized resistance to viruses. In their evolution, some viruses have developed strategies that do not harm the host sufficiently to cause extinction of the host - and the virus. Nevertheless, in some instances virus-host coevolution has resulted in disease-producing relationships that cause economic losses and suffering of the animals and birds. Conventional breeding methods will remain the principal approach to the improvement of disease resistance in livestock but in some instances, introduction of new genetically engineered resistance mechanisms may be justified.

Prerequisites for the design of new resistance mechanisms include good knowledge of the viral genome and life cycle (keeping to a minimum the biological cost of the new strategies to the host) and of the probability that the strategies will be overcome by viral evolution. A combination of gene targeting techniques with embryonic stem cells, when such cells become available for livestock, will greatly facilitate the introduction of new, genetically engineered virus resistance. All livestock with new resistance mechanisms will have to be subjected to thorough testing. There are several possible strategies for the development of new resistance mechanisms in livestock. The transgenes to be designed for such strategies can act at various phases in the viral life cycle. Ideally, expression of the transgenes should be triggered by the presence of the inducing virus, otherwise the resistance mechanism should remain 'silent'. Strategies that prevent viral entry to the host are expected to be most valuable as they could eliminate all damage to the host caused by the virus.

\section{ACKNOWLEDGMENTS}

The author wishes to express his gratitude to the Institut national de la recherche agronomique, for the provision of a pleasant, friendly, and stimulating working environment at the Laboratoire de génétique factorielle at Jouy-en-Josas, France, where he compiled this review during a six month stay in 1995. Helpful comments and suggestions were provided during the preparation of the manuscript by LB Crittenden, RI Hamilton, and JL Spencer.

\section{REFERENCES}

Bai J, Payne LN, Skinner MA (1995) HPRS-103 (exogenous avian leukosis virus, subgroup J) has an $e n v$ gene related to those of endogenous elements EAV-O and E51 and an E element found previously only in sarcoma viruses. $J$ Virol 69, 779-784

Ban J, Portelle C, Altaner C, Horion B, Milan D, Krchnak V, Burny A, Kettmann R (1993) Isolation and characterization of a 2.3 kilobase-pair cDNA fragment encoding the binding domain of the bovine leukemia virus cell receptor. $J$ Virol 67, 1050-1057

Bastardo JW, Holmes IH (1980) Attachment of SA-11 rotavirus to erythrocyte receptors. Infect Immunol 29, 1134-1140

Bates P, Young JAT, Varmus HE (1993) A receptor for subgroup A Rous sarcoma virus is related to the low density lipoprotein receptor. Cell 74, 1043-1051 
Bates P, Young JAT, Crittenden LB, Varmus HE (1994) The cloned receptor for subgroup A avian leukosis virus maps to TVA*S, the dominant gene for susceptibility to subgroup A virus. Proc Int Conf on Comp Gene Mapping in Terrestrial and Aquatic Vert, Oslo, Feb 7-11, 1994, p 61

Bertoletti A, Sette A, Chisari FV, Penna A, Levrero M, De Carli M, Flaccadori F, Ferrari C (1994) Natural variants of cytotoxic epitopes are T-cell receptor antagonists for antiviral cytotoxic T-cells. Nature $369,407-410$

Blomquist MC, Hunt LT, Barker WC (1984) Vaccinia virus 19-kilodalton protein: relationship to several mammalian proteins, including two growth factors. Proc Natl Acad Sci USA 81, 7363-7367

Bohmann D, Bos TJ, Admon A, Nishimura T, Vogt PK, Tijan R (1987) Human proto-oncogene $c$-jun encodes a DNA binding protein with structural and functional properties of transcription factor AP-1. Science 238, 1386-1392

Boyle JF, Wiesmiller DG, Holmes KV (1987) Genetic resistance to mouse hepatitis virus correlates with absence of virus-binding activity on target tissues. $J$ Virol 61, 185-189

Bradley MO, Chrisey LA, Hawkins JW (1992) Antisense therapeutics. In: Gene Regulation: Biology of Antisense RNA and DNA, (RP Erickson, JG Izant, eds) Raven Press, New York, 285-293

Brown JP, Twardzik DR, Marquardt H, Todaro GJ (1985) Vaccinia virus encodes a polypeptide homologous to epidermal growth factor and transforming growth factor. Nature 313, 491-492

Brown DW, Blais BP, Robinson HL (1988) Long terminal repeat (LTR) sequences, env, and a region near the $5^{\prime}$ LTR influence the pathogenic potential of recombinants between Rous-associated virus types 0 and 1. J Virol 62, 3431-3437

Brown KE, Anderson SM, Young NS (1993) Erythrocyte P antigen: cellular receptor for B 19 parvovirus. Science 262, 114-117

Brown KE, Hibbs JR, Galinella G, Anderson SM, Lehman ED, McCarthy P, Young NS (1994) Resistance to parvovirus B19 infection due to lack of virus receptor (erythrocyte P antigen). New Engl $J$ Med 330, 1192-1196

Burness AT, Pardoe IU (1983) A sialoglycopeptide from human erythrocytes with receptor-like properties for encephalomyocarditis and influenza viruses. J Gen Virol $64,1137-1148$

Carr JP, Zaitlin M (1991) Resistance in transgenic tobacco plants expressing a nonstructural gene sequence of tobacco mosaic virus is a consequence of markedly reduced virus replication. Mol Plant-Microbe Interact 4, 579-585

Choi A, Lee P (1988) Does the beta-andrenergic factor receptor function as reovirus receptor? Virology 163, 191-197

Clements JE, Wall RJ, Narayan O, Hauer D, Schoborg R, Sheffer D, Powell A, Carruth LM, Zin MC, Rexroad E (1994) Development of transgenic sheep that express the visna virus envelope gene. Virology 200, 370-380

Collins AR (1994) Human coronavirus OC43 interacts with major histocompatibility complex class I molecules at the cell surface to establish infection. Immunol Invest 23, 313-321

Cotten M, Birnstiel ML (1989) Ribozyme-mediated destruction of RNA in vivo. EMBO $J$ 8, 3861-3866

Crittenden LB, Smith EJ, Fadly AM (1984) Influence of endogenous viral (ev) gene expression and strain of exogenous avian leukosis virus (ALV) on mortality and ALV infection and shedding in chickens. Avian Dis 28, 1037-1056

Crittenden LB (1991) Retroviral elements in the genome of the chicken: implication for poultry genetics and breeding. Crit Rev Poultry Biol 3, 73-109 
Dawson WO, Hilf ME (1992) Host-range determinants of plant viruses. Annu Rev Plant Physiot Plant Mol Biol 43, 527-555

De Haan P, Gielen JJL, Prins M, Wijkamp IG, Van Scheppen A, Peters D (1992) Characterization of RNA-mediated resistance to tomato spotted wilt virus in transgenic tobacco plants. Biotechnology 10, 1133-1137

Delmas B, Gelfi J, Kut E, Sjostrom H, Noren O, Laude H (1994) Determinants essential for the transmissible gastroenteritis virus receptor interaction reside within a domain of aminopeptidase $\mathrm{N}$ that is distinct from the enzymatic site. $J$ Virol $68,5216-5224$

De Wit PJGM (1992) Molecular characterization of gene-for-gene systems in plant fungus interactions and the application of avirulence genes in control of plant pathogens. Annu Rev Phytopathol 30, 391-418

De Zoetten GA (1991) Risk assessment: do we let history repeat itself? Phytopathology $81,585-586$

Dobzhansky T (1959) Genetics and the Origin of Species. Columbia University Press, New York

Dougherty J, Temin HM (1988) Determination of the rate of base pair substitution and insertion mutation in retrovirus replication. $J$ Virol $62,2817-2822$

Edington BV, Nelson RS (1992) Utilization of ribozymes in plants. Plant viral resistance. In: Gene Regulation: Biology of Antisense RNA and DNA (RP Erickson, JG Izant, eds), Raven Press, New York, 209-221

Falk BW, Bruening G (1994) Will transgenic crops generate new viruses and new diseases? Science 263, 1395-1396

Fenwick ML, McMenamin MM (1984) Early virion-associated suppression of cellular protein synthesis by herpes simplex virus is accompanied by inactivation of mRNA. $J$ Gen Virol 65, 1225-1228

Fingeroth JD, Weis JJ, Tedder TF, Strominger JL, Biro PA, Fearon DJ (1984) EpsteinBarr virus receptor of human B lymphocytes is the CD3 receptor CR2. Proc Natl Acad Sci USA 81, 4510-4516

First NL, Sims MM, Park SP, Kent-First MJ (1994) Systems for production of calves from cultured bovine embryonic cells. Reprod Fert Develop 6, 553-562

Fitchen JH, Beachy RN (1993) Genetically engineered protection against viruses in transgenic plants. Annu Rev Microbiol 47, 739-763

Flor HH (1956) The complementary genetic systems in flax and flax rust. Adv Genet 8, $29-54$

Fujinami RS (1994) Molecular mimicry: virus modulation of the immune response. In: Handbook of Neurological Disease and Therapy, Vol 27 (WC Kendall, WG Stroop, eds), Marcel Dekker, New York, 103-114

Gama LT, Smith C, Gibson JP (1992) Transgene effects, introgression strategies and testing schemes in pigs. Anim Prod 54, 427-440

Garber EH, Chute J, Condra L, Gotlib R, Colonno RJ, Smith RG (1991) Avian cells expressing the murine $\mathrm{Mx} 1$ protein are resistant to influenza virus infection. Virology $180,754-762$

Gavora JS (1990) Disease genetics. In: Poultry Breeding and Genetics (RD Crawford, ed), Elsevier Science Publishers, Amsterdam, 805-846

Gavora JS, Roper AM, Mucha J, Prochazka R, Benkel B, Nagai J, Sabour MP, Babiuk L, Falconer M, Turner JD (1994) Introduction of resistance to bovine rotavirus by gene transfer. Proc 5th World Congress on Genetics Applied in Livestock Production. Guelph, ON, Canada, 362-365

Gavora JS, Benkel B, Spencer JL, Gagnon C, Crittenden LB (1995a) Influence of the alv6 recombinant avian leukosis virus transgene on production traits and infection with avian tumor viruses in chickens. Poult Sci 74, 852-963 
Gavora JS, Spencer JL, Benkel B, Gagnon C, Emsley A, Kulenkamp A (1995b) Endogenous viral genes influence infection with avian leukosis virus. Avian Pathol 24, 653-664

Gerlach WL, Llewellyn D, Haseloff J (1987) Construction of a plant disease resistance gene from the satellite RNA of tobacco ringspot virus. Nature 328, 802-805

Golemboski DB, Lomonossoff GP, Zaitlin M (1990) Plants transformed with tobacco mosaic virus nonstructural gene sequence are resistant to the virus. Proc Natl Acad Sci USA 87, 6311-6315

Gott JM, Shub DA, Marsh T, Pace N, Altman S (1986) Multiple self-splicing introns in bacteriophage T4, evidence from autocatalytic GTP labelling of RNA in vitro. Cell 47, 81-87

Greene AE, Allison RF (1994) Recombination between viral RNA and transgenic plant transcripts. Science 263, 1423-1425

Greve JM, Davis G, Meyer AM, Forte CP, Yost SC, Marlor CW, Karmack ME, McClelland A (1989) The major human rhinovirus receptor is ICAM-1. Cell 56, 297-303

Hamilton RI (1980) Defences triggered by previous invaders: viruses. In: Plant Disease - An Advanced Treatise (JG Horsfall, EB Cowling, eds), Academic Press, New York, 279-303

Hanafusa T, Hanafusa $\mathrm{H}$, Myiamoto T (1970) Recovery of a new virus from apparently normal chick cells by infection with avian tumor viruses. Proc Natl Acad Sci USA 76, 1797-1803

Helenius A, Morein B, Fries EEA (1978) Human (HLA-A and HLA-B) and murine (H2K and H2D) histocompatibility antigens are cell surface receptors for Semliki Forest virus. Proc Natl Acad Sci USA 75, 3846-3850

Hilder VA, Gatehouse AMR (1991) Phenotypic cost to plants of an extra gene. Transgenic Res 1, 54-60

Hofer F, Gruenberger M, Kowalski H, Machat H, Huettinger M, Kuechler E, Blass D (1994) Members of the low density lipoprotein receptor family mediate cell entry of a minor group common cold virus. Proc Natl Acad Sci USA 91, 1939-1942

Hope TJ, Klein PN, Elder ME, Parslow TG (1992) Trans-dominant inhibition of human immunodefficiency virus type 1 rev occurs through formation of inactive protein complexes. $J$ Virol 66, 1849-1855

Ikeda H, Odaka $\mathrm{T}$ (1983) Cellular expression of murine leukemia virus gp70-related antigen on thymocytes of uninfected mice correlates with $F v-4$ gene-controlled resistance to Friend leukemia virus infection. Virology 128, 127-139

Inglis SC (1982) Inhibition of host protein synthesis and degradation of cellular mRNAs during infection by influenza and herpes simplex virus. Mol Cel Biol 2, 1644-1648

Johnson RD, Spear PG (1989) Herpes simplex virus glycoprotein D mediates interference with herpes simplex virus infection. $J$ Virol $63,819-827$

Kawchuk LM, Martin RR, McPherson J (1991) Sense and antisense RNA-mediated resistance to potato leafroll virus in Russet Burbank potato plants. Pol Plant-Microbe Interact 4, 227-253

Klatzman D, Champagne E, Charmaret S, Gruest J, Geutard D, Hercend T, Gluckman JC, Montagnier L (1984) T-lymphocyte T4 molecule behaves as the receptor for human retrovirus LAV. Nature 312, 767-768

Knipe DM (1991) Virus-host-cell interactions. In: Fundamental Virology (BN Fields, DM Knipe et al, eds) Raven Press, New York, 267-290

Krug RM, Shaw M, Broni B, Shapiro G, Haller O (1985) Inhibition of influenzal viral mRNA synthesis in cells expressing the interferon-induced $M x$ gene proct. $J$ Virol 56 , 201-206

Malo D, Skamene E (1994) Genetic control of host resistance to infection. Trends Genet $10,365-371$ 
Martini N, Egen M, Runtz I, Strittmatter G (1993) Promoter sequences of a potato pathogenesis-related gene mediate transcriptional activation selectively upon fungal infection. Mol Gen Genet 236, 179-186

McFadden G, Kane K (1994) How DNA viruses perturb functional MHC expression to alter immune recognition. Adv Canc Res 63, 117-209

McLaren LC, Holland JJ, Syverton JT (1959) The mammalian cell-virus relationship. I. Attachment of poliovirus to cultivated cells of primate and nonprimate origin. $J$ Exp Med 83, 475-485

Mendelsohn C, Wimmer E, Racaniello V (1989) Cellular receptor for poliovirus: molecular cloning, nucleotide sequence, and expression of a new member of the immunoglobulin superfamily. Cell $56,855-865$

Mendez E, Arias CF, Lopez S (1993) Binding to sialic acids is not an essential step for entry of animal rotaviruses to epithelial cells in culture. $J$ Virol $67,5233-5259$

Michel F, Dujon B (1986) Genetic exchange between bacteriophage T4 and filamentous fungi? Cell 46, 323-324

Miller DG, Miller AD (1994) A family of retroviruses that utilize related phosphate transporters for cell entry. J Virol 68, 8270-8276

Miyazawa M, Fujisawa R (1994) Physiology and pathology of host immune responses to exogenous and endogenous murine retroviruses - from gene fragments to epitopes. Tohoku J Exp Med 173, 91-103

Miyazawa M, Nose M, Kawashima M, Kyogoku M (1987) Pathogenesis of arteritis of SL/Ni mice. Possible lytic effect of anti-gp70 antibodies on vascular smooth muscle cells. J Exp Med 166, 890-908

Neurath A, Kent S, Strick N, Parker K (1986) Identification and chemical synthesis of a host cell receptor binding site on hepatitis B virus. Cell 46, 429-436

Nevins JR (1986) Control of cellular and viral transcription during adenovirus infection. CRC Crit Rev Biochem 19, 307-322

Norkin LC, Ouelette J (1976) Cell killing by simian virus 40: variation in the pattern of lysozomal enzyme release, cellular enzyme release, and cell death during productive infection of normal and simian virus 40-transformed simian cell lines. J Virol 18, 48-57

Olah Z, Lehel C, Anderson W, Eiden M, Wilson CA (1994) The cellular receptor for gibbon ape leukemia virus is a novel high affinity sodium dependent phosphate transporter. $J$ Biol Chem 269, 25426-25431

Oldstone MAB (1993) Rous-Whipple Award Lecture: Viruses and diseases of the twentieth century. Am J Pathol 143, 1241-1249

Owens RA, Trempe JP, Chejanovsky N, Carter BJ (1991) Adeno-associated virus rep proteins produced in insect and mammalian expression systems: wild-type and dominantnegative mutant proteins bind to the viral replication origin. Virology 184, 14-22

Parker R, Muhlrad D, Deshler JO, Taylor N, Rossi JJ (1992) Ribozymes: principles and designs for their use as antisense and therapeutic agents. In: Gene Regulation: Biology of Antisense RNA and DNA (RP Erickson, JG Izant, eds) Raven Press, New York, 55-70

Payne LN (1985) Genetics of cell receptors for avian leukosis viruses. In: Poultry Genetics and Breeding (GW Hill, JM Mason, D Hewitt, eds) Br Poult Sci Symp 1-16

Pincus SH, Rosa PA, Spangrude GJ, Heinemann JA (1992) The interplay of microbes and their hosts. Immunol Today 13, 471-473

Post LE, Mackem S, Roizman B (1981) Regulation of alpha genes of herpes simplex virus: expression of chimeric genes produced by fusion of thimidine kinase with alpha gene promoters. Cell 24, 555-556

Powell PA, Stark DM, Sanders PR, Beachy RN (1989) Protection against tobacco mosaic virus in transgenic plants that express tobacco mosaic virus antisense RNA. Proc Natl Acad Sci USA 86, 6949-6952 
Robinson HL, Astrin SM, Senior AM, Salazar FH (1981) Host susceptibility to endogenous virus: defective glycoprotein-expressing proviruses interfere to infections. $J$ Virol 40, 745-751

Roizman B (1991) Multiplication of viruses. In: Fundamental Vitrology (BN Fields, DM Kinney et al, eds), Raven Press, New York, 87-94

Rose JK, Trachsel H, Leong D, Baltimore D (1978) Inhibition of translation of poliovirus: inactivation of a specific initiation factor. Proc Natl Acad Sci USA 75, 2732-2736

Salter DW, Crittenden LB (1989) Artificial insertion of a dominant gene for resistance to avian leukosis virus into the germ line of the chicken. Theor Appl Genet 77, 457-461

Sanford JC, Johnston SA (1985) The concept of parasite-derived resistance-deriving resistance genes from parasite's own genome. $J$ Theor Biol 113, 395-405

Scheid A, Choppin PW (1988) Protease activation mutants of Sendai virus. Activation of biological properties by specific proteases. Virology $239,265-277$

Serfling E, Jasin M, Shaffner W (1985) Enhancers and eukaryotic gene transcription. Trends Genet 1, 224-230

Smith D, Byrn R, Marsters S, Gregory T, Groopman J, Capon B (1987) Blocking of HIV-1 infectivity by a soluble, secreted form of the CD4 antigen. Science 238, 1704-1707

Smith C, Meuwissen THE, Gibson JP (1987) On the use of transgenes in livestock improvement. Ann Breeding (Abstr) 55, 1-10

Spear PG, Shieh MT, Herold BC, WuDunn D, Koshy TI (1992) Heparan sulfate glycosaminoglycans as primary cell surface receptors for herpes simplex virus. Adv Exp Med Biol 313, 341-353

Staeheli P, Pravtcheva D, Lundin JG, Acklin M, Ruddle F, Lindenmann J, Haller O (1986) Interferon-regulated influenza resistance gene $M x$ is localized on mouse chromosome 16. $J$ Virol 58, 967-969

Staskawitz BJ, Ausubel FM, Baker BJ, Ellis JG and Jones JDG (1995) Molecular genetics of plant disease resistance. Science $268 ; 661-667$

Strauss EJ, Strauss JH, Levine AJ (1991) Virus evolution. In: Fundamental Virology (BN Fields, DM Knipe et al, eds) Raven Press, New York, 167-190

To RY, Booth SC, Neiman PE (1986) Inhibition of retroviral replication by antisense RNA. Mol Cell Biol 61, 3004-3012

To RY, Neiman PE (1992) The potential for effective antisense inhibition of retroviral replication mediated by retroviral vectors. In: Gene Regulation: Biology of Antisense RNA and DNA (RP Erickson, JG Izant, eds), Raven Press, New York, 261-271

Tsunetsugu-Yakota Y, Matsuda S, Maekawa M, Saito T, Takemori T, Tekebe Y (1992) Constitutive expression of the nef gene suppresses human immunodeficiency virus type 1 (HIV-1) replication in monocyte cell lines. Virology 191, 960-963

Tyler KL, Fields BN (1991) Pathogenesis of viral infections. In: Fundamental Virology (B Fields, DM Knipe et al, eds), Raven Press, New York, 191-239

Valentine RC, Pereira HG (1965) Antigens and structure of the adenovirus. $J$ Mol Biol $13,13-20$

Wang H, Kavanaugh MP, Kabat D (1994) A critical site in the cell surface receptor for ecotropic murine retroviruses required for amino acid transport but not for viral reception. Virology 202, 1058-1060

Ward PL, Roizman B (1994) Herpes simplex genes: the blueprint of a successful human pathogen. Trends Genet 18, 267-274

Watson JD, Hopkins N, Roberts JW, Steitz JA, Weiner A (1987) The Molecular Biology of the Gene. The Benjamin-Cumming Publishing Co, Menlo Park, CA

Weis W, Brown J, Cusack S, Paulson J, Skehel J, Wiley D (1988) Structure of the influenza virus hemagglutinin complexed with its receptor, sialic acid. Nature 333, 426-431 
Wilson TMA (1993) Strategies to protect crop plants against viruses: pathogen-derived resistance blossoms. Proc Natl Acad Sci USA 90, 3134-3141

Witter RL (1988) Very virulent Marek's disease viruses: importance and control. Proc XVIII World Poultry Congress, Nagoya, Japan, 92-98

Yamaya J, Yoshioka M, Meshi TMA, Shaw JG (1988) Cross protection of transgenic tobacco plants expressing a mild strain of tobacco mosaic virus. Mol Gen Genet 215, 173-175

Yokomori K, Lai MM (1994) Mouse hepatitis virus receptors: more than a single carcinoembryonic antigen. Arch Virol Suppl 9, 461-471 